\title{
Testing a novel dual receptor agonist for treatment of type $\mathbf{2}$ diabetes mellitus
}

\section{The results of this trial provide support for a thorough evaluation of efficacy and safety in a phase III programme}

Glucagon-like peptide 1 (GLP1) receptor agonists are used to treat patients with type 2 diabetes mellitus (T2DM). However, many patients taking these drugs do not achieve their target $\mathrm{HbA}_{\mathrm{lc}}$ levels, meaning that new treatment strategies are needed. A paper published in the Lancet has now reported positive results for a novel dual receptor agonist that targets the receptors for GLP1 and glucose-dependent insulinotropic polypeptide (GIP) in the treatment of patients with T2DM.

"Unimolecular, multi-functional peptides that combine GLP1 receptor agonist activity with GIP activity have been suggested to increase the therapeutic potential, compared with selective GLP1 receptor agonists," explains corresponding author Axel Haupt. The researchers developed a novel molecule (LY3298176) that has activity at the GIP and GLP1 receptors. Early results from a proofof-concept study were promising, leading the researchers to undertake a phase IIb study.

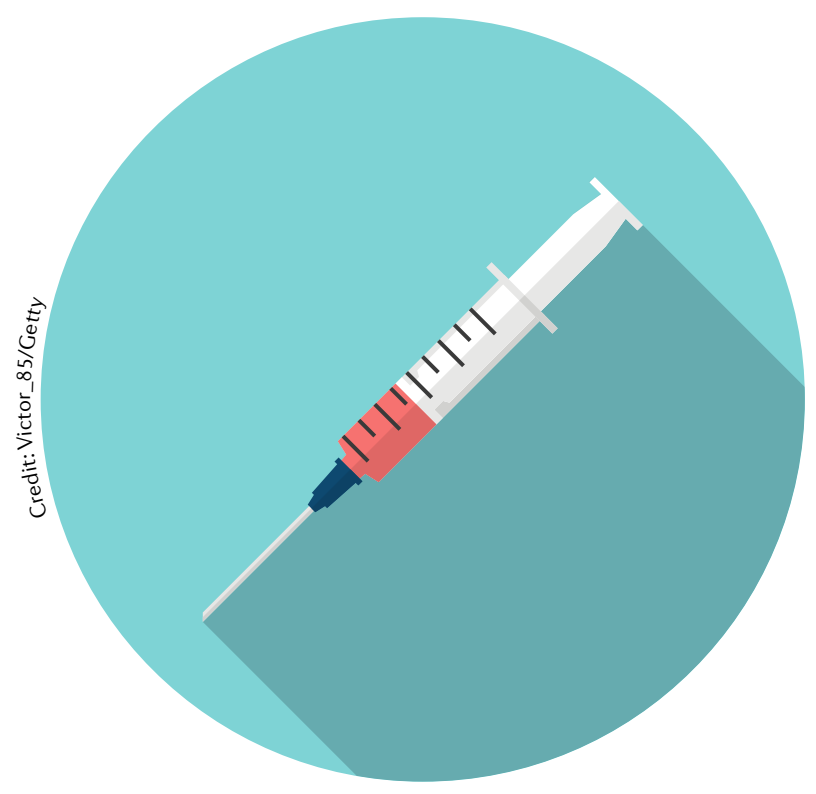

In this double-blind, randomized phase IIb study, 318 patients with poorly controlled T2DM were randomly assigned to one of six weekly treatments: placebo, $1.5 \mathrm{mg}$ dulaglutide (a selective GLP1 receptor agonist) or LY3298176 (at $1 \mathrm{mg}, 5 \mathrm{mg}, 10 \mathrm{mg}$ or $15 \mathrm{mg}$ ). To improve tolerability, patients in the $10 \mathrm{mg}$ and $15 \mathrm{mg}$ LY3298176 groups were titrated up to the final dose over several weeks. The patients were treated for 26 weeks and then followed up for an additional 4 weeks to assess safety outcomes. Treatment was undertaken at 47 sites across four countries (Poland, Puerto Rico, Slovakia and the USA). The patients had all been diagnosed with T2DM at least 6 months before enrolment in the trial and had T2DM that was poorly controlled with lifestyle interventions or metformin.

"At 26 weeks, the primary analysis showed a robust dose response compared with placebo throughout the entire dose range of LY3298176," reports Haupt. Compared with baseline, patients who received $15 \mathrm{mg}$ LY3298176 saw a $2.4 \%$ reduction in levels of $\mathrm{HbA}_{1 \mathrm{c}}$, those on $10 \mathrm{mg}$ had a $2.0 \%$ reduction, those on $5 \mathrm{mg}$ had a $1.6 \%$ reduction, patients on $1 \mathrm{mg}$ had a $0.7 \%$ reduction, patients on dulaglutide had a $1.1 \%$ reduction and those receiving the placebo had a $0.1 \%$ increase. These reductions resulted in up to $90 \%$ of patients receiving LY3298176 achieving $\mathrm{HbA}_{1 \mathrm{c}}$ levels $<7.0 \%$, compared with $52 \%$ of the patients receiving dulaglutide and $12 \%$ of those in the placebo group (32.7\% in the $1 \mathrm{mg}$ group, $69.1 \%$ in the $5 \mathrm{mg}$ group, $90.0 \%$ in the $10 \mathrm{mg}$ group and $77.4 \%$ in the $15 \mathrm{mg}$ group).

The patients who received LY3298176 also lost more weight $(0.9 \mathrm{~kg}, 4.8 \mathrm{~kg}, 8.7 \mathrm{~kg}$ and $11.3 \mathrm{~kg}$ in the $1 \mathrm{mg}, 5 \mathrm{mg}, 10 \mathrm{mg}$ and $15 \mathrm{mg}$ groups, respectively) than those in the dulaglutide $(2.7 \mathrm{~kg})$ or placebo $(0.4 \mathrm{~kg})$ groups. In addition, more than one-third of patients who received $10 \mathrm{mg}$ or $15 \mathrm{mg}$ LY3298176 lost $\geq 10 \%$ of their starting body weight.

Importantly, the safety profile of the dual agonist was similar to that of dulaglutide. The most common adverse effects were dose-related incidences of nausea, vomiting and diarrhoea. These effects were mild-to-moderate and tended to be transient. Of note, adverse effects were more frequent in the $15 \mathrm{mg}$ LY3298176 treatment group and led to increased treatment discontinuation in this group. "Despite the strong glycaemic effect no patient experienced severe hypoglycaemia," notes Haupt.

The researchers conclude that LY3298176 has better efficacy than dulaglutide and has an acceptable safety and tolerability profile. In particular, they note that the $5 \mathrm{mg}$ and $10 \mathrm{mg}$ doses of LY3298176 showed greater improvements regarding glycaemia and body weight yet similar adverse effects compared with dulaglutide. "The addition of GIP activity might complement the pharmacology of selective GLP1 receptor agonists," concludes Haupt. "The results of this trial provide support for a thorough evaluation of efficacy and safety in a phase III programme with an optimized administration regimen." Phase III trials of LY3298176 (termed SURPASS) will be initiated by the end of the first quarter of 2019.

Claire Greenhill

ORIGINAL ARTICLE Frias, J. P. et al. Efficacy and safety of LY3298176, a novel dual GIP and GLP-1 receptor agonist, in patients with type 2 diabetes: a randomised, placebo-controlled and active comparator-controlled phase 2 trial. Lancet https://doi.org/10.1016/S0140-6736(18)32260-8. (2018) 